\title{
WIND EFFECTS ON BUILDINGS AND STRUCTURES
}

$\mathrm{S}^{\mathrm{a}}$ OME three hundred scientists and engineers repre$\checkmark$ senting twenty-one different countries gathered recently at the National Physical Laboratory, Teddington, for an International Conference on Wind Effects on Buildings and Structures which had been organized by the Laboratory in collaboration with the Building Research Station, the Institution of Civil Engineers and the Institution of Structural Engineers.

In view of the extent to which the safe and economic design of all forms of building and structure is dependent on a proper understanding of the effects of wind, it is perhaps surprising to learn that the Conference at Teddington represented the first major attempt in this field to bring together the research worker and the practising engineer. Most of the twenty-four papers presented at the conference were concerned with the wide range of research at present in progress at various establishments throughout the world and, naturally enough, much reference was made to the use of the wind tunnel as the chief research tool. However, it was encouraging to hear that with the development of new techniques and instrumentation it is proving less difficult than in the past to obtain measurements of wind loading on full-scale buildings.

The Conference was organized into six sessions each under the chairmanship of a distinguished engineer or scientist and each covering a different aspect of the problem. The first session, at which Sir Gordon Sutherland, director of the National Physical Laboratory, took the chair was restricted to the official opening and to an introductory paper by Mr. C. Scruton of the National Physical Laboratory. In his paper, Mr. Scruton reviewed the present position with regard to wind effects on buildings and structures. $\mathrm{H}_{\theta}$ directed attention to the fact that the terms of reference of the conference were restricted to the static and dynamic stability of structures and of structural members in wind and excluded such effects as the generation of noise, the promotion of fire and the penetration of rain. With the foregoing exceptions, the action of wind was classified into the static and dynamic effects; the former referring to the steady (time average) forces and pressures tending to give the structure or its component members a steady displacement and the latter to the tendency to set the structure oscillating. Mention was made of the Tay Bridge disaster of 1879 which prompted the engineers to make allowance for the wind in the design of the Forth Railway Bridge. He went on to consider the subjects of design wind speed, determination of the shape and pressure coefficients and the oscillatory effects of wind. Under each heading he stated the problems involved and demonstrated the part played by the individual contributions of the various authors to the understanding of the subject as a whole. In conclusion, a plea was made that the conference would stimulate a movement towards better liaison between the interested organizations in the various countries so that research could be co-ordinated and the results disseminated on a wider and more systematic basis than had been possible hitherto.

In session 2 the first two papers were both concerned with the structure of the wind. Mr. H. C. Shellard of the Meteorological Office (Britain) indicated some of the problems involved in making wind measurements and discussed the factors influencing the application of such measured data to the design of buildings and structures where the site conditions might be very different from those at the meteorological station where the measurements are actually mado. Prof. A. G. Davenport (Canada) developed this theme further by introducing the concept of referring design wind speeds to the gradient height and relating the speed at lesser heights by factors depending on the terrain at the site of the structure. The statistical properties of turbulent wind were also discussed both in terms of the spectra and of the return period for the maximum wind speed. The probability theory used in his analysis of wind data yielded increased wind speeds as the life period for the structure is increased.

Papers by Mr. C. W. Newberry (Britain) and Dr. R. Pris (France) were both concerned with the measurement of wind pressures on full-scale buildings. The authors discussed the problems of instrumentation which had hitherto prevented comprehensive full-scale studies.

Session 3 was devoted to a discussion of the wind-tunnel techniques used for the investigation of wind effects on buildings and structures. The shape and pressure coefficient data in common use have been derived almost entirely from wind-tunnel experiments so that it is essential that such experiments should reproduce as closely as possible the behaviour of full-scale buildings and struc. tures in the natural wind. A technique for reproducing the vertical gradient of the speed of the natural wind was described by Mr. N. Franck (Denmark). This was a practical interpretation of Jensen's model law and consisted of the application of coatings to the wind-tunnel floor ahead of the model with a variety of roughnesses designed to reproduce the gradient and turbulence properties of wind approaching over different types of terrain. Prof. W. D. Baines (Canada) reported on his work on the effects of wind gradient on tall skyscraper buildings and showed how, in the presence of a wind gradient, air currents can be induced to flow down the front faces of such buildings to give strong winds at street level. The wind-tunnel studies at present being undertaken in France and Belgium were presented in papers by Dr. R. Pris (France) and M. P. E. Colin and R. D'Have (Belgium) respectively. Both papers described work carried out in open-jet wind-tunnels using models mounted on ground plates. The last paper in this session, entitled "Model Simulation of Wind Effects on Structures" and presented by Mr. R. E. Whitbread (Britain), summarized the approach to wind-tunnel testing of models which has been adopted at the National Physical Laboratory. As well as discussing the effects of wind gradient, the paper introduced the concept of representing the dynamic properties of structures on models of reduced linear scale so that both the static and dynamic behaviour of a structure could be examined in the wind tunnel. The methods were illustrated by reference to an exhibition of models and techniques used at the National Physical Laboratory. The models included one of the General Post Office Tower for Central London and another of a $400-\mathrm{ft}$. office block. A further consideration introduced into the paper was that of the errors introduced into force and pressure measurements made on wind-tunnel models by an interference effect known as wake blockage. It was pointed out that this effect was of particular significance for tests on building models owing to the wide wakes generated by such models.

From meteorological observations and wind-tunnel investigations come most of the data used to formulate the wind loading clauses in the codes of engineering practice for building. With the previous discussions of both these aspects it was appropriate that papers on codes of practice should follow. These were provided by the papers of M. N. Esquillan (France) and Dr. M. Jensen and Mr. N. Franck (Denmark), who described the proposed revisions of the codes of practice for their respective countries.

The second half of this session introduced a different note into the proceedings which was to persist throughout the remaining papers, namely, the dynamic response of 
structures to wind. The present codes of practice havo been based on wind-tunnel test data obtained under steady wind conditions; whereas the data so obtained are applied to structures subject to the natural wind which can bo both highly turbulent and continually varying in speed and direction. The assumption of a steady wind for design purposes implies that the fluctuations in speed and direction that do occur in the natural wind are so irregular and random that the structure does not respond to them any differently from its behaviour in a steady wind of the same average speed. This assumption was, however, challenged by Prof. A. G. Davenport (Canada). His paper on the buffoting of structures by gusts presentod the rosults of an analysis of the responso of a flexible structure to horizontal turbulonce and showed, at least for structures of low natural frequency, that the deflexions produced can sometimes exceed the effect of the equivalent steady wind of the same average spoed. In a second paper on the same subjoct, Mr. R. I. Harris, of the Electrical Research Association (Britainh described work with a similar approach which formed part of an extensive but not yet complote study of the special problems of gust effects on very tall transmission masts.

Both sessions on the final day of the Conference were devoted to problems of the oscillation of structures due to the action of steady winds. Since the collapse of the first Tacoma Narrows Bridge in 1940 designs for longspan suspension bridges havo been subjected to extensive wind-tunnel testing prior to their erection. Even to-day, 23 years after the disaster, it is still desirable to carry out tests on models to ensure the stability of a particular design. Mr. D. E. J. Walshe (Britain) described the techniques which have been developed at the National Physical Laboratory for this type of testing. He discussed the use of spring-mounted models of typical sections of the suspended roadways and the requirements for such models to representative of the complote bridge. Papers from the United States, Norway and France discussed the techniques used in these countries and demonstrated the international aspect of this particular problem.

Aorodynamic oscillation featured yet again in session 6 , the final session of the Conference, when another problem of international interest, namely that of the galloping of electric power transmission lines, was the subject of four successivo papers. The term 'galloping' has been used to describe the large amplitude oscillations which can be set up in transmission lines by wind. The cause can usually be attributed to certain de-stabilizing characteristics of the steady wind forces which often prevail when the transmission lines become coated with ice. In this session papors from Canada and the United States predominated. However, a paper presented by Mr. D. J. W. Richards of the Central Electricity Research Laboratorios (Britain) described a case of galloping which occurred in non-icing conditions on the 5,310-ft. span of the $275-\mathrm{kV}$ power crossing of the Rivers Severn and Wye. Wind-tunnel tests on sections of the conductor showed that the instability arose from peculiar aerodynamic effects associatod with the lay of the outer layer of the conductor strands. Wrapping the conductor with polyvinyl chloride tape to produce a smooth profile was found to be an effoctive method of introducing stability to the crossing.

Slender structures with low natural frequencies such as stacks, towers and masts have a tendency to oscillate in response to the shedding of vortices at the natural frequency of the structure. That the vast majority of such structuros do not oscillate can be attributed to the fact that they possess sufficient inherent structural damping to cancel out the aerodynamic excitation effect.

Modern methods of construction, although perhaps more economical and structurally efficient, tend to decrease the amount of structural damping and hence increase the liability to wind-excited oscillation. In his paper on this subject Mr. C. Scruton (Britain) mentioned these effects, and others, which influence the aerodynamic stability of stacks, towers and masts. The use of strakes with sharpedged rectangular section wound as helices around the surface of cylindrical sections had proved to be a most effective device for the prevention of vortex-excited oscillations. A similar mothod was described in a paper by Professor Nakagawa (Japan). He had adopted a system of wire ropes as strakes, for application to tall stacks of welded stool construction in Japan. However, his advocation of the use of wire ropes appoared to be in disagreement with the statemont made by Mr. Scruton in his paper that rounded strakes had been shown to be less offective than those of rectangular section.

R. E. Whitbread

\title{
INFORMATION PER SE
}

\author{
By DR. PAUL S. HENSHAW \\ Division of Biology and Medicine, U.S. Atomic Energy Commission, Washington
}

$\mathrm{R}^{\mathrm{s}}$ ECEIPT and use of information is a feature in all living systems.

The information used by living systems is of three types: inherited, acquirod and generated. Inherited information is that brought into organisms at the moment of conception; acquired is that brought in continuously during life by means of the sensory shield; and generated is that formed inside the system by interaction.

The means by which acquired information is received and developed varies widely among species.

Systems in organisms for processing acquired information have undergone evolutionary change comparable with that which has occurred in systems having to do with othor functions.

Along with ability to detect and transduce stimuli, and along with ability to transmit information laden impulsos, has come an increased ability to comprehend, to understand and to know, also an incroased ability to imagine, feel, evaluate and make judgments. Acquisition of the more specialized information processing capabilities, and of the greater emotional capacities, have coincided with elaboration of the cerebral cortex.
In the human species, that is, the species considered to have the most advanced cerebral cortex, the ability to develop and utilize information greatly transcends that of other species. The human mind--the means by which we think-can be regarded as tho most highly elaboratod. product of ovolution.

Information is an entity apart from the means by which it is processed, the symbols by which it is represented, or the responses made to it. Messages contain intelligonce (dispositional, organized, usable and available information), but as such do not themselves constitute intelligence.

Information can be transmitted and stored by means of impulses and symbols, but it exerts an influence only after removal from the oncodod message and interaction with other information, as can happen in a cell, a brain or a computer.

Information can bo rogarded as existing in piecos or concopts, but probably not as units. Information, as such, is not amenable to quantitation in a manner comparable with that which applies to entities having foree, mass or colour. 